\title{
Tramways in Urban Areas: An Overview on Safety at Road Intersections
}

\author{
Marco Guerrieri ${ }^{1}$ (D)
}

Received: 26 July 2018/Revised: 26 November 2018/Accepted: 4 December 2018/Published online: 11 December 2018

(C) The Author(s) 2018

\begin{abstract}
Although the accident number involving trams is comparatively very limited to the total road accident number, the consequences of tram crashes are very serious, especially when pedestrians are run over. The new power supply technologies (e.g. catenary-free systems) allow to build tram networks, even in old town centres and pedestrian areas, with additional increased risk of pedestrian casualties. This will require specific design solutions and traffic regulations for road safety as described in this paper, with particular regard to vulnerable users (i.e. pedestrians and cyclists), especially near intersections and pedestrian crossings. Therefore, the research analyses the road accident rate and its evolution in the last 10 years with specific focus on Italian tramways. The main risk conditions and the strategies used worldwide to improve the safety of tramway system in the urban context are described. The main countermeasures to reduce accident risks are aimed at better warning road users of specific risk conditions. Other countermeasures are designed to install suitable facilities on road platforms for better informing users of tramway system, for limiting or temporarily prohibiting turning movements or manoeuvrings and for properly channelling pedestrian and vehicle flows with the purpose to avoid or reduce interference with trams.
\end{abstract}

Keywords Tramway systems - Road intersections - Road safety $\cdot$ Urban context

Marco Guerrieri

marco.guerrieri@tin.it

1 DICAM, University of Trento, Via Mesiano 77, 38123 Trento, Italy

Communicated by Xuesong Zhou.

\section{Introduction}

In order to ease traffic congestions and lower air pollution levels in big cities, a lot of countries are increasingly resorting to tramway systems, considered as environmentally sustainable, reliable and able to meet high mobility demands [1]. The new ground-level power supply technologies (e.g. APS by Alstom, TramWave by Ansaldo) and the developing systems like the induction technique (e.g. Bombardier Primove) allow tramways to be perfectly compatible with old town centres from both architectural and urban planning viewpoints, in that they are catenaryfree [2].

However, tramway accidents have been more frequent since incentive schemes have encouraged public transport use. It is widely known that people underestimate the probability of being involved in a negative event (e.g. road accidents, diseases, economic problems) during their lifetime, in that they consider themselves to be somehow invulnerable: an attitude defined unrealistic optimism in psychology [3]. Consistent with this empirical evidence, road users (pedestrians, motor/cyclists and motorists) underestimate the risk of meeting tramway accidents because of low tram speed and careful tram drivers [4].

Moreover, risk perception is affected by user type and age. It has been precisely observed that [5]:

- young pedestrians (15 29 years old) perceive interactions with trams as globally riskier to themselves and the others than pedestrians of different ages;

- young car drivers and cyclists (15 29 years old) are unrealistically optimist and underestimate the accident risk.

Tramway systems, therefore, pose numerous problems - to some extent still unsolved — on road safety and 
protection of the socalled vulnerable users (e.g. cyclists, pedestrians, disabled people), especially at road intersections which are absolutely crucial for the operating conditions of the global road network (GRN) in terms of functionality and safety.

Although tramway accidents are very limited in number if compared to the total road accidents, their consequences, especially when involving pedestrians, are so serious that cannot be neglected by transportation and highway engineers. In the light of the brief considerations above, this paper first analyses the road accident rate and its evolution in the last 10 years with specific regard to operating Italian tramways and then outlines the main strategies introduced worldwide to improve the tram safety system in the urban environment.

Such strategies are aimed at better warning road users of specific risk conditions on the one hand, and on the other, they are designed to install suitable facilities on road platforms:

- for better informing users of tramway system (also by means of acoustic signals);

- for limiting or temporarily prohibiting turning movements or manoeuvrings;

- for properly channelling pedestrian and vehicle flows so as to avoid or reduce interference with trams.

\subsection{Classification of Tramway Systems}

Modern tramways are mass public transport systems in urban and suburban areas characterised by commercial speeds of $12 \sim 30 \mathrm{~km} / \mathrm{h}$ and actual passenger capacity of the order of 6000 passengers/h/per direction. They can be classified as follows $[6,7]$ :

- Common corridor (class E) Railway vehicles are mixed with road vehicles and pedestrians;

- Exclusive Separated Corridor (Class D) Grooved rails are also used, but they are separated from the general traffic by means of horizontal lining or obstacles accessible to pedestrians;

- Exclusive Tram Corridor (Class C) The existing road is used solely for the movement of the tram while the remaining road width is pedestrianised;

- Exclusive Protected Corridor (Class B) The tramway is completely separated from the circulation of road vehicles and pedestrians;

- Fully Exclusive Corridor (class A) Tramway vehicles move as in the previous case (class B) on flat bottom rails, at grade, or underground or elevated section.

The most distinctive functional and geometric characteristics based on the type system are given in Table 1 .
In addition to conventional catenary-fed trams, new catenary-free technologies are available nowadays [8]:

- Ground-Level Power Supply (GLPS) Power continuously supplied to the vehicle at ground level via direct contact with a conductor or inductively (Ansaldo TramWave, Alstom APS etc.);

- Onboard Energy Storage System (OESS) Power stored on the vehicle, using flywheels, batteries (Ni-MH, LiIon etc.), supercapacitors or a combination thereof, recharged periodically via regenerative braking and contact with a power conductor;

- Onboard Power Generation System (OPGS) Power continuously generated on the vehicle as required via hydrogen fuel cells, micro-turbines or diesel engines.

These systems have received acclaim for eliminating the need for overhead wires and preserving the aesthetic form of the dense urban centres. The catenary-free technologies are increasingly used around the world.

\subsection{Growth Trend in the Tramway Transport System and Accident Rate: The Italian Case}

Rail transport in urban/suburban areas (tramway system) went into decline in the 1970s (Fig. 1) but it has been rediscovered and boosted since $2000[9,10]$. In fact, the total domestic traffic in the urban tram transport has increased in the last 10 years from 1053 million passengers-km in 2005 to 1305 million passengers-km in 2015 [11]. Also the suburban tram transport has significantly grown from 50 million passengers-km in 2005 to 85 million passengers-km in 2015.

In 2005 , the total extension of the urban/suburban tramway network in operation was $457 \mathrm{~km}$ and $516 \mathrm{~km}$ in 2015. Despite the upward trend, the private mode still prevails over the public means of transport: precisely in 2015, the percentage transport mode distribution was [11]: $4.5 \%$ motorcycles, $83.8 \%$ private vehicles, $11.7 \%$ public transport.

In 2016 in Italy, there were in all 175,791 road accidents with seriously injured casualties, among which were 3283 died in 30 days and 249,175 wounded [12].

The available data indicate a relatively safe tram transport system. Suffice it to say that in the same 2016, there were 46 one-vehicle accidents (of which 41 involving pedestrians) and 116 crashes involving other vehicles [12].

It is also worth considering that thanks to the positive transport demand trend and the consequent tramline expansion in old town centres together with the increasingly efficient catenary-free systems, accident numbers are certainly doomed to grow.

In order to make the tramway transportation system safer, a careful investigation should be conducted into the 
Table 1 Features and characteristic values related to tramway systems. Source: Adapted from [7]

Minimum horizontal curvature radius

Types of track integration

Types of stops integration

Distance between two successive stops

Types of power supply system (catenary overhead system integration)

Vehicle length

Vehicle width

Commercial speed per tramway corridor category (without tram priority at level intersections $)^{\mathrm{a}}$

Impact of tram priority at signals on tram commercial speed
$R=20 \sim 25 \mathrm{~m}$, preferred value $R \geq 30 \mathrm{~m}$

$R=15 \sim 18 \mathrm{~m}$ at shunting tracks

A single track per direction at the opposite sides of the roadway

A double track on one side of the roadway

Central alignment (double track)

Stop with centre (Island) platform

Stop with laterally staggered platforms

Stop with laterally opposed platforms

$200 \mathrm{~m} \sim 800 \mathrm{~m}$

Central mast and opposite cantilevers

Lateral mast and double-track cantilevers

Catenary connected to laterally opposed masts

Catenary connected to building facades

Mixed catenary connection (on one side to lateral masts and on the other to building facades)

Simple: $8 \sim 18 \mathrm{~m}$, Articulated: $18 \sim 30 \mathrm{~m}$, Multiarticulated: $25 \sim 45 \mathrm{~m}$

$2.20 \sim 2.65 \mathrm{~m}$ (normal track gauge)

Class (E): $V_{\mathrm{c}}=12 \sim 15 \mathrm{~km} / \mathrm{h}$

Class (D): $V_{\mathrm{c}}=16 \sim 18 \mathrm{~km} / \mathrm{h}$

Class (C): $V_{\mathrm{c}}=18 \sim 20 \mathrm{~km} / \mathrm{h}$

Class (B): $V_{\mathrm{c}}=20 \mathrm{~km} / \mathrm{h}$

Class (A): $V_{\mathrm{c}}=30 \mathrm{~km} / \mathrm{h}$

Commercial speed increase by $15 \% \sim 25 \%$ for corridor classes (D) $\left(V_{\mathrm{cmax}}=22.5 \mathrm{~km} / \mathrm{h}\right)$ and (B) $\left(V_{\mathrm{cmax}}=25 \mathrm{~km} / \mathrm{h}\right)$
Fig. 1 Tram network and passenger expansion in Italy

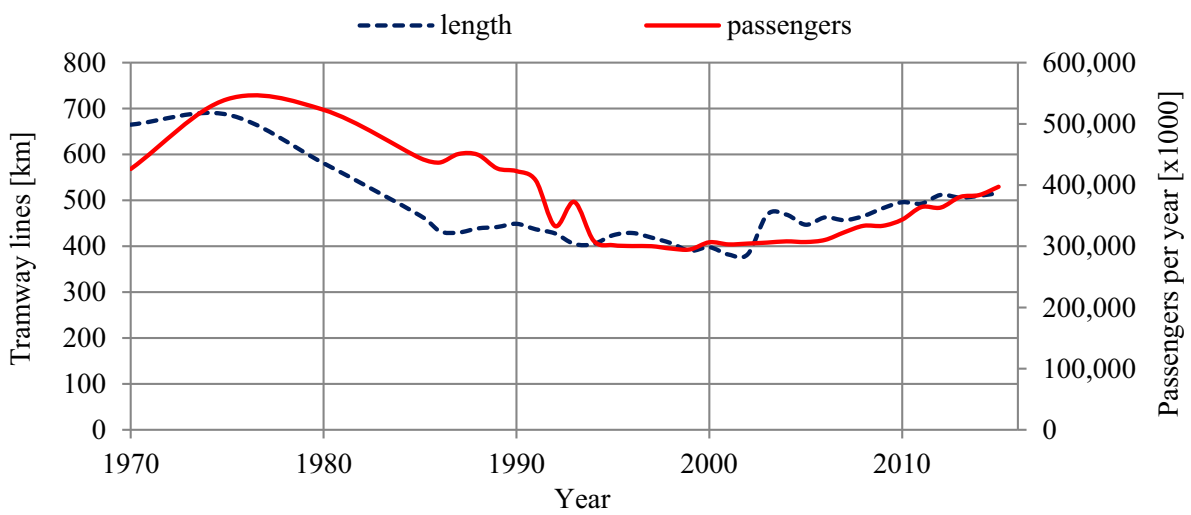

most common accident causes to find technical solutions for reducing accident risks to the utmost.

\section{Risks and Safety at Road Intersections}

\subsection{Accidents with Motor Vehicles, Motorcycles and Bicycles}

Studies carried out in the USA on 16 different tramlines [13-15], put into operation between 1999 and 2004, have shown that the most frequent accident is the tram collision with a car turning left at an intersection; apparently, it takes place even if the tram is properly signalled. More precisely, the following risk conditions can vary depending on the tram location [13-15]:

(a) Tramway on the Middle of the Platform in a TwoWay Road (Fig. 2a) Left-turn manoeuvres for vehicles are controlled by dedicated traffic lights so as not to conflict with trams having right of way. At these junctions, offences are not numerous and often 
Fig. 2 a-d Layout of Tramway

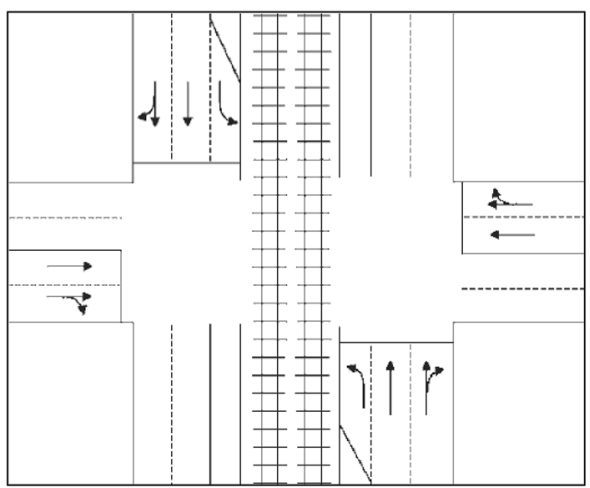

(a)

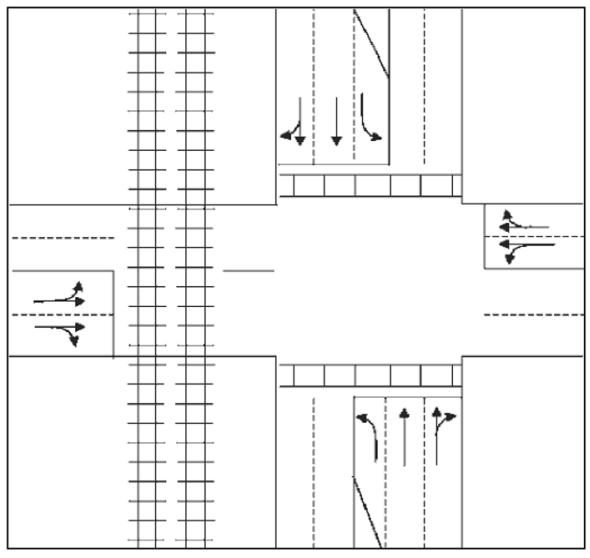

(c)

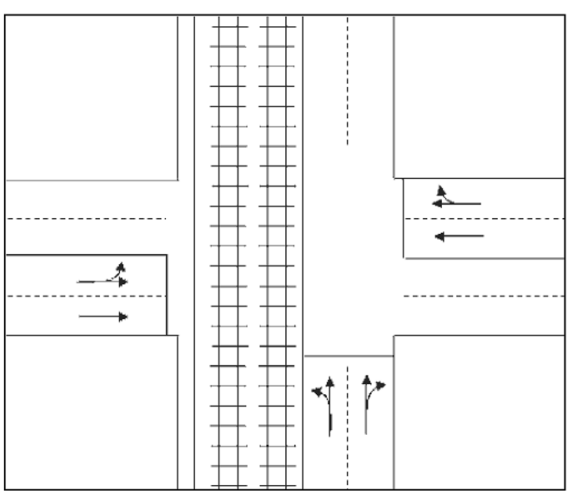

(b)

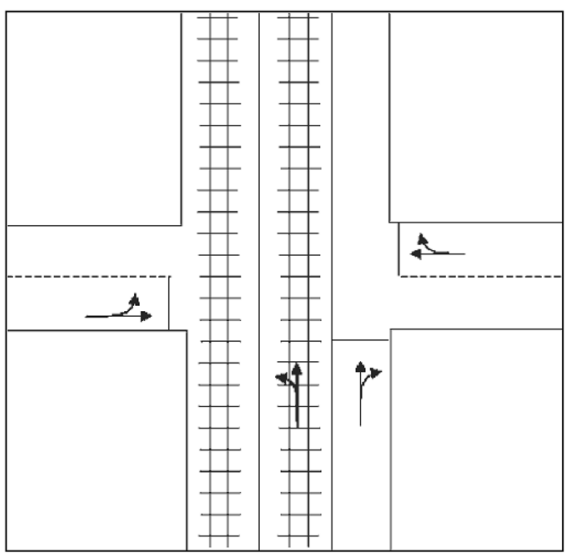

(d) due to misperception and misinterpretation of road signs. The most frequent accident involves a left-turn vehicle from the same route as the road reserved for trams, and a tram coming from behind and going on the same direction which can only be seen by rearview mirrors;

(b) Tramway on the Edge of One-Direction Carriageway (Fig. 2b) The most frequent accident involves left-turn vehicles and trams from the same direction if the tramline is located on the left edge of the main road. On the other hand, if the tramline is installed on the right one, accidents more often involve vehicles turning right from the main road into the side street;

(c) Tramway Crossing the Road at an Intersection (Fig. 2c) Generally accidents are caused by nonobservance of the red light next to the tramline crossing point, or by misinterpretation (or confusion) from drivers mistaking the traffic lights at the junction for that dedicated to the tramway;

(d) Tramway on One-Direction Carriageway with Shared Lane Use with Traffic Flow (Fig. 2d) In this case, one or more lanes are used by both trams and vehicles. It means that besides accidents mentioned in (c) where trajectories have angles of incidence around $90^{\circ}$, there can be collisions between trams and vehicles, or involving an isolated vehicle, for example bicycles or motorcycles losing balance when their wheel moves on an axle.

In all cases, left-turn manoeuvres at intersections by themselves account for $47 \%$ of the total accidents involving cars and trams [15]. Such an occurrence can be attributed to the following major causes (Table 2) [16]:

- Non-observance of Traffic Signs (Disobedience) Drivers perceive their accident risk involvement to be low or, at most, as much as they do at common road intersections, while road intersections with tramway are intrinsically risky, and definitely riskier on average;

- Misperception of Traffic Signs Users can be careless or do not fully comply with traffic regulations by confusing the green light attributed to a certain manoeuvre with the red one for turning left in a given time interval;

- Users' Cognitive Errors and Violated Expectations The high number of manoeuvres at these intersections and the great complexity of regulating tram and vehicle 
Table 2 Accident causes involving motor vehicles and trams at road intersections

Accidents involving trams at road intersections: summary description

1 The sign system does not properly inform users about prohibition of turn manoeuvres

2 Drivers start their turn manoeuvres immediately after the green light is off or just before the red light appears thus blocking the intersection

3 Confusion about the interpretation of the green signal which allows drivers to cross the intersection and the red light to turn left

4 Drivers mistake the signs dedicated to trams for those for vehicular traffic

5 When the left turn is no longer allowed because of the tram construction, irregular drivers may, nevertheless, do it in that they think it is still permitted

6 Undisciplined users can violate the highway code rules also at intersections on on-street tramways unaware of the higher risk rate in the latter

7 The stop signal for a certain manoeuvre can be activated well in advance of the arrival of the means of transport; consequently, drivers can violate it in that they think to have a reasonable time margin to perform their desired manoeuvre

8 Signs can be activated too late for the expected arrival of the trams

9 In shared lanes, motor vehicles can clash with the trams

10 Horizontal and vertical signs and traffic regulation systems can sometimes be redundant or inconsistent with one another, thus making road users unsure

11 Users wait to perform their desired manoeuvres on the tramway truck

traffic flows make these intersections extremely hard to be properly perceived, especially by unfamiliar users with these specific types of intersections.

More often than not, tramway accidents (involving both vehicles and pedestrians) are wrongly classified as "human errors". On this point, it is worth observing that if it is true that a lot of accidents are a consequence of human mistakes, it is certain likewise that too often there are design deficiencies in the transport system and/or road infrastructure which play a crucial role in causing such an error.

With special regard to monitored accidents, also at an international level, vehicles generally perform turning manoeuvres which are not allowed or inhibited at certain time intervals just because there are design mistakes such as inconsistent/absent road signs or physical structures to prevent vehicles from performing a turn manoeuvre (e.g. kerbs, barriers), etc.

Other causes of accidents at conventional (Fig. 3) or innovative road intersections [17] can be:
- road axles do not cross each other perpendicularly [14];

- users perform left-turn manoeuvre when the traffic light is red trying to anticipate the oncoming tram;

- users execute left-turn manoeuvre following a platoon of vehicles which have already performed the same manoeuvre, thus violating the tram right of way;

- users carry out left-turn manoeuvres immediately after the very end of the green light phase (if the intersection is controlled by traffic lights);

- users ignore the left/right-turn prohibition and intersect the tramway;

- users confuse tram and intersection sign systems;

- the intersection layout can determine errors in perception and/or behaviour.

Thus, road intersections should be designed (or replanned) with the aim of ensuring high safety levels also after a new tramline is activated.
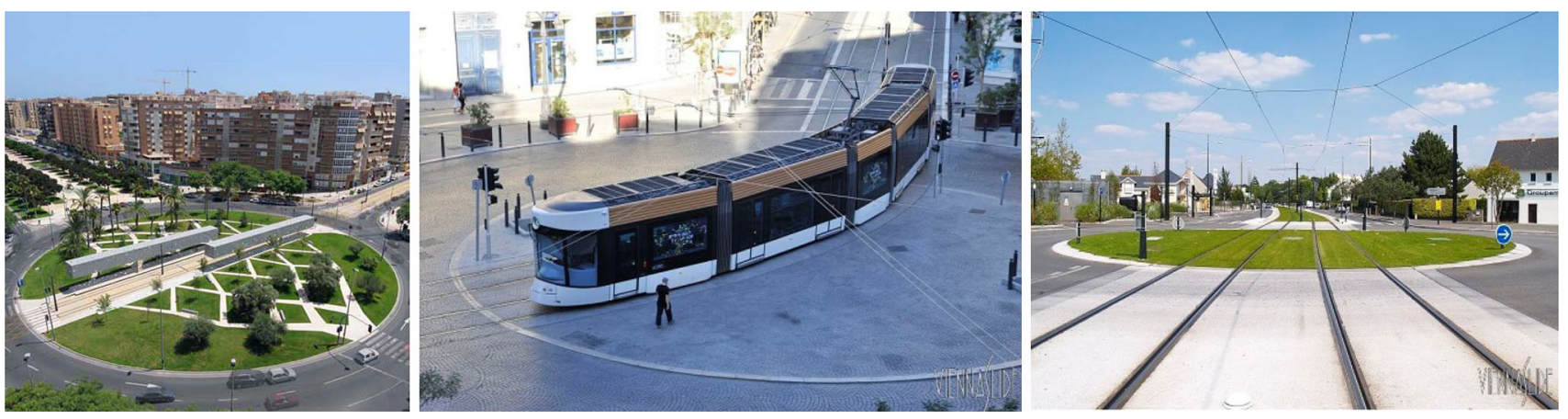

Fig. 3 Roundabout intersections with tramway lines 
In this regard, the main countermeasures to reduce accident risks involving motor vehicles are listed shortly below:

- the stop signal must be moved $4.5 \mathrm{~m}$ prior to the tramline;

- visibility triangles must be ensured at intersections;

- drivers must be able to see on their right or left from the stop position, so as to estimate the correct lag from the oncoming tram and safely perform or abandon their manoeuvres;

- trams approaching the intersection must reduce travelling speed in line with their performance class (with special regard to braking distance);

- in case of a tramway laid on a road with the right of way on the converging streets, the track axle should coincide with the carriage axle if the latter has a twoway direction. On the other hand, in case of one-way roads, the tram should move in the same direction as vehicles;

- driveways should be removed where possible;

- tramway track should be differentiated from road pavement by colour, paving type, texture, etc. especially for shared-use lanes (Figs. 4 and 5);

- unsurmountable kerbs (usually not larger than $0.60 \mathrm{~m}$ ) must be well visible, even at night, and therefore catadioptric reflectors should be installed ("cat's eyes");

- mountable central reservation kerbs must be fully visible day and night.

In some cases, the installation of proper barriers blocking vehicular flows should be preferable, thus giving trams the right of way. For example, at conventional atgrade intersections, the most dangerous manoeuvre is the left turning (Fig. 6); a barrier properly built could inhibit that movement for long enough to allow the tram to pass through. On the other hand, at roundabout intersections, barriers installed along the ring lane would form queues on the ring and consequently on entry arms, which actually never occurs at roundabouts where the right of way is given to vehicles on the circulation lanes.
It is worth underlining that such technical devices improve safety but unfortunately they can provide poor levels of service at intersections due to the queues and delays, sometimes thought to be intolerable by users. Therefore, while planning, transportation analysis (if necessary, through traffic microsimulation techniques) is required to quantitatively assess the effects of the technical measures just described (Fig. 7).

\section{Accidents Involving Pedestrians}

Accidents involving pedestrians often take place because pedestrians do not notice the oncoming tram, even near a pedestrian crossing.

The main countermeasure to reduce the collision risk consists in carefully leading the pedestrian traffic to cross carriageway at pre-established paths. Such an objective can be met by physically delimiting pedestrian paths with railings along pavements and making them accessible only at pedestrian crossings; the measure allows to limit the exposure to accident risks and can be utilised, especially at non-signalised intersections.

On the other hand, at signalised intersections, it would be advisable to install pedestrian traffic lights with acoustic signals to inform users of the best time to cross the road. Moreover, traffic lights phases would be adapted to inhibit left turnings, very problematic in terms of pedestrian/vehicle visibility, during pedestrian crossings. As for the road geometry, sidewalks might be reprofiled in order to induce speed reduction as well as improve pedestrian/vehicle visibility. In this regard, a possible functional upgrading layout is illustrated in Fig. 8.

In order to further improve safety conditions, an "allred" phase (e.g. 2-s long) can be added in traffic light timing so as to give pedestrians (especially, the old and/or disabled people) extra time to complete their crossing.

Sometimes an exclusive pedestrian phase can be introduced to stop all vehicles at the junction and allow pedestrian crossings in all directions, including diagonally. The areas with massive pedestrian flows can be regulated
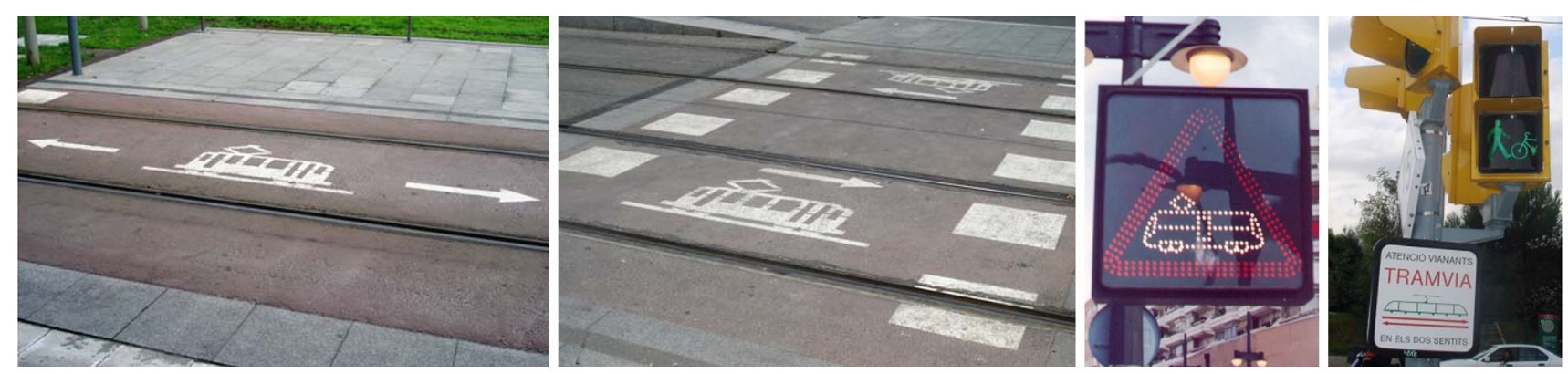

Fig. 4 Horizontal and vertical sign systems-Barcelona Spain [7] 

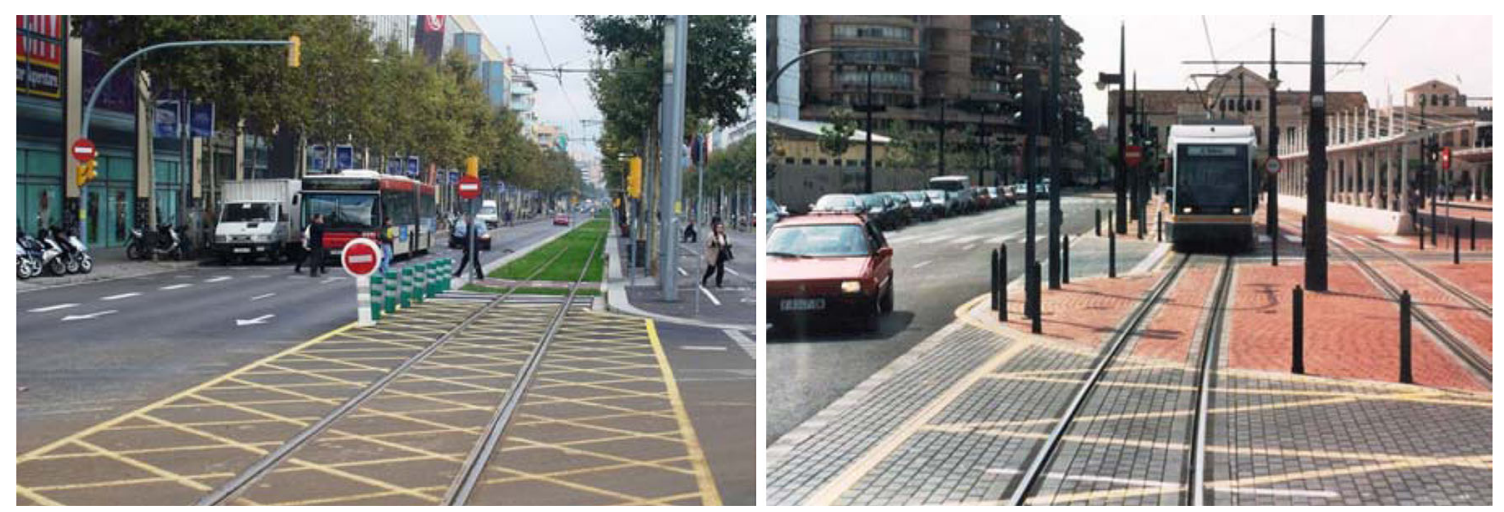

Fig. 5 Road carriageway near an intersection with a tramway line (Spain) [7]
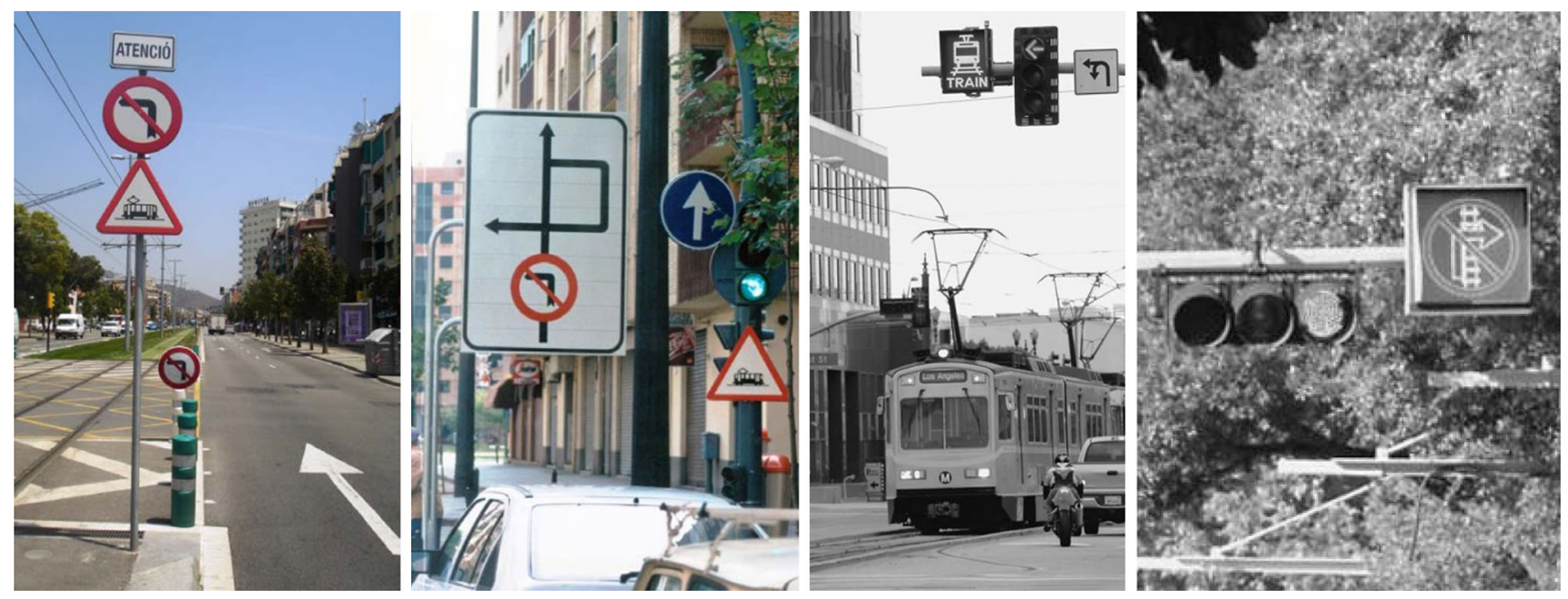

Fig. 6 Vertical no-turn signs. Trams in Barcelona and Valencia [7]
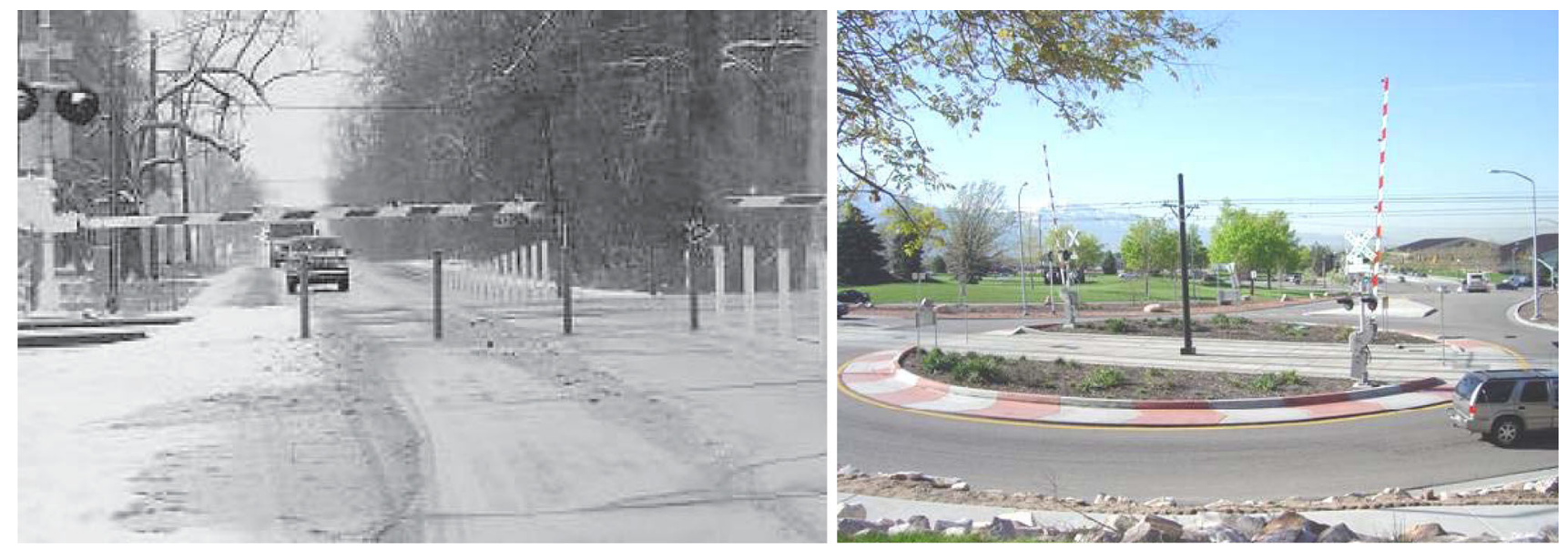

Fig. 7 Barrier installations at at-grade and roundabout intersections

by preventing vehicles from turning into side streets; this can be feasible, for instance, near schools or public buildings.

In order to calculate the pedestrian green, the phasing can be arranged in exclusive pedestrian and pedestrian/ vehicle phases. In case of exclusive pedestrian phase (EPP), the pedestrian green time can be calculated with one of the following formulae [18]: 

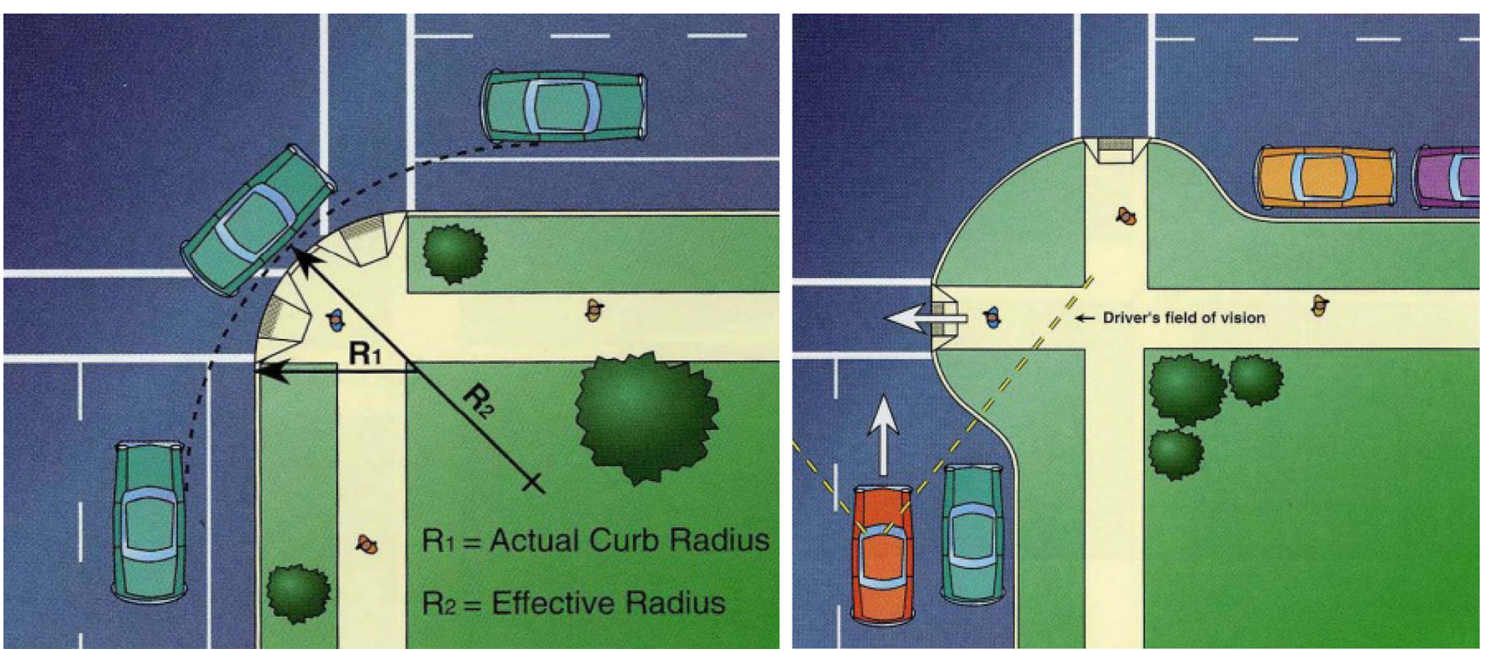

Fig. 8 Geometric modifications of a road intersection by sidewalk reprofiling

$G_{\mathrm{p}}=3.2+0.27 \cdot N_{\mathrm{p}}+\frac{L}{v_{\mathrm{p}}} \quad($ if $b \leq 3.00 \mathrm{~m})$

$G_{\mathrm{p}}=3.2+0.81 \cdot \frac{N_{\mathrm{p}}}{b}+\frac{L}{v_{\mathrm{p}}} \quad($ if $b>3.00 \mathrm{~m})$

In which

$G_{\mathrm{p}}=$ pedestrian green (s);

$N_{\mathrm{p}}=$ pedestrian number per interval;

$L=$ crossing length $(\mathrm{m})$;

$b=$ crossing width $(\mathrm{m})$;

$v_{\mathrm{p}}=$ pedestrian speed (15th percentile is assumed as $1.2 \mathrm{~m} / \mathrm{s}$ ).

In cases where an exclusive phase is not foreseen, the green time should be added to the intergreen time of the corresponding vehicle flow to verify that their sum is large enough for the pedestrian crossing.

Traffic lights should then be provided with a timer to indicate the amount of time left to cross the road (Fig. 9).

In San Francisco, the results from traffic light timers showed that such devices allow to reduce the accident number by $25 \%$. Other measures which can be taken into consideration according to the specific contexts are (Fig. 10):

- lighted pedestrian paths to limit accident risks even at night;

- clearly signalling the stop position for pedestrians and cyclists: this signal must be laid also on the road paving with a pictogram made, for instance, of bicolour (red/ white) cold plastic. This measure is appropriate when [19]:

(1) local tram speed exceeds $24 \mathrm{~km} / \mathrm{h}$ and (2) the stop position of the pedestrian crossing is not clear enough.

Sometimes it might be convenient to misalign the pedestrian path just before crossing the carriageway by means of a barrier system via a Z-shaped trajectory
(Fig. 10). In this case, the objective is double: on the one hand to slow pedestrians down, on the other to catch their attention to vehicle and tram flows with the path deviation, before crossing over.

\section{Tramway Truck Degradation at Road Intersections}

A lot of accidents taking place on shared-use lanes (Common corridor-class E) are due to tramway truck defects. In case of element pavements, the most common deterioration types are $[11,20]$ :

(a) rutting in close proximity to tram rails;

(b) stone indentation (surface displacement of series elements);

(c) subsidence and local cracks due to single stones;

(d) anomalous joint openings and/or removal of the internal sealing.

The most frequent deterioration types in asphalt pavements are surface cracks and permanent deformations which make both the tramway truck and therefore the pneumatic/pavement interface irregular (Fig. 11).

Often, the surface cracks and other railway track permanent deformations occur in road intersections due to the vehicles acceleration and deceleration.

In the abovementioned cases, there may occur adherence loss or anomalous conditioning for vehicle driving which can lead especially cyclists and motorcyclists to lose balance and fall off their vehicles.

Numerical simulations on the cyclist driving behaviour at tramway rails $[11,20]$ have pointed that:

(1) if cyclists ride in a straight direction parallel to the rail, the height variation of the pavement elements 

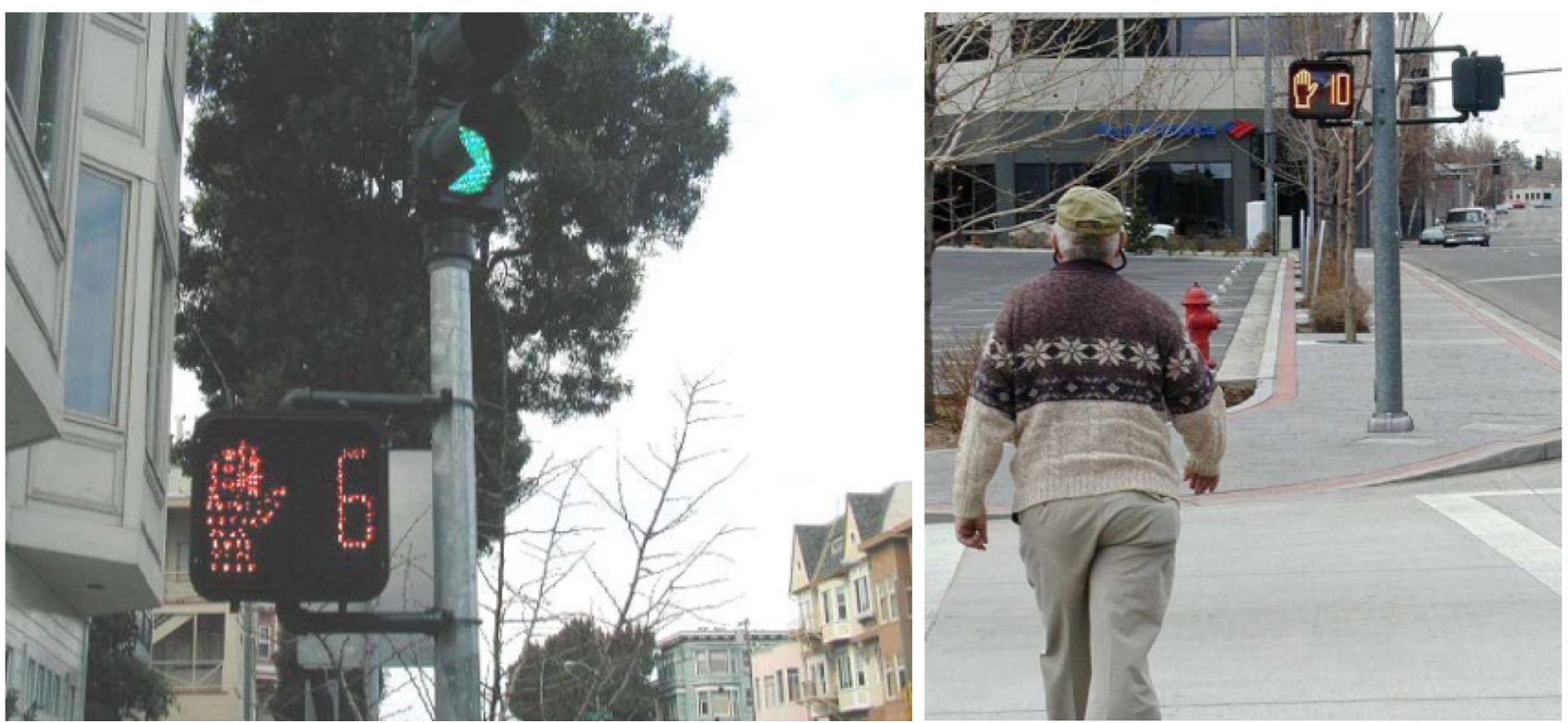

Fig. 9 Traffic lights with timer
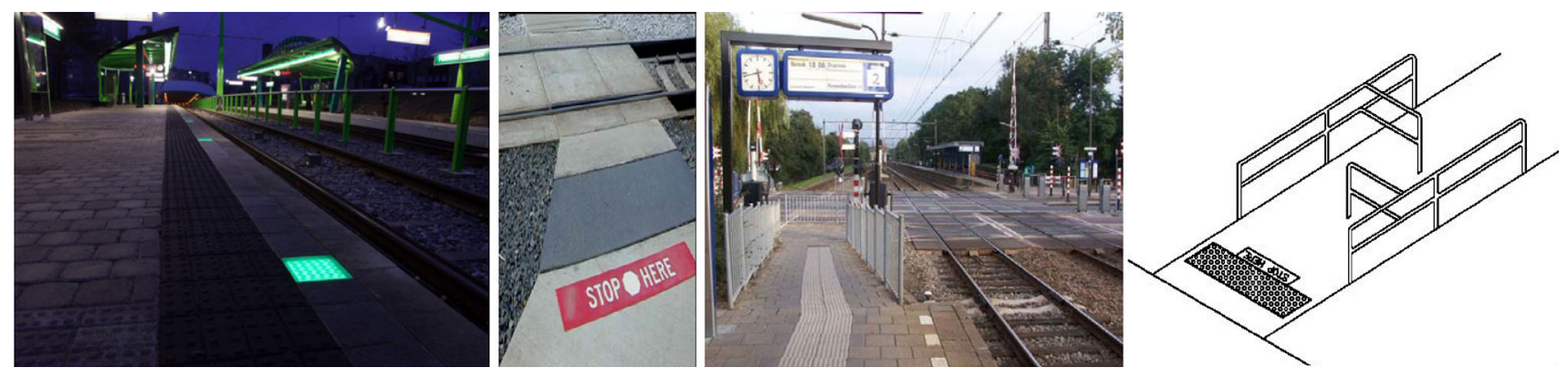

Fig. 10 Protected pedestrian paths
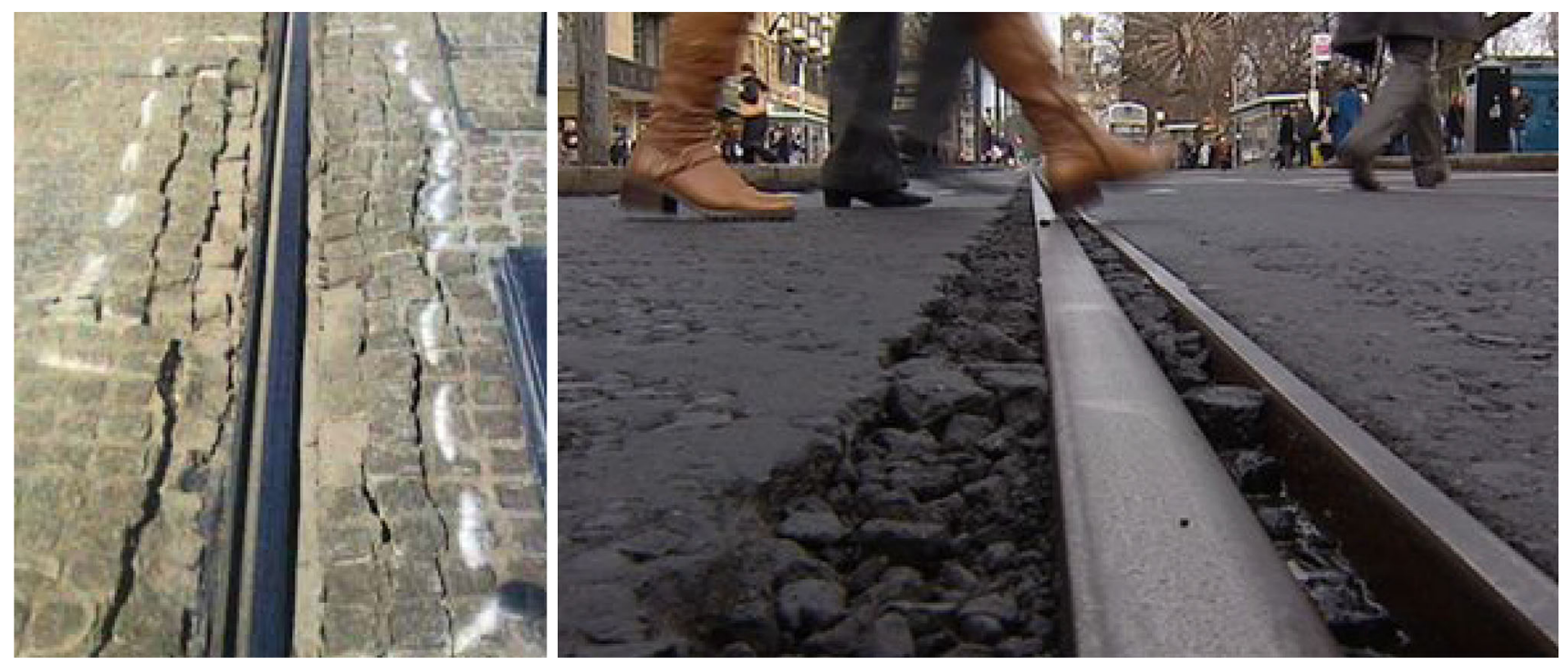

Fig. 11 Damages to road and tramway superstructures [20] 
must not be above $30 \mathrm{~mm}$, whereas if the speed is below $20 \mathrm{~km} / \mathrm{h}$, the height discontinuity can be tolerated from 20 to $30 \mathrm{~mm}$; finally, if discontinuities are below $20 \mathrm{~mm}$, the driving speed can maintain safety conditions up to $50 \mathrm{~km} / \mathrm{h}$;

(2) if cyclists ride along a curve, the safety speed to prevent falling from vehicles must be lower than $40 \mathrm{~km} / \mathrm{h}$ even if altimetric discontinuities in the pavement are not above $10 \mathrm{~mm}$; an acceptable risk level occurs when the discontinuity ranges between 10 and $20 \mathrm{~mm}$, and the riding speed is lower than $20 \mathrm{~km} / \mathrm{h}$.

Considering all the points illustrated above, tramway truck and adjacent areas subject to deterioration from tram dynamic stresses and consequent loss of functionality in rather short periods of time should be continually tested with dynamic auscultations. To this end, besides the visual surveys especially on joints-which, if irregular, allow rainwater to infiltrate into the deepest layers of the superstructure with consequent deterioration phenomena, specific instrumental surveys of track deflections (e.g. falling weight deflectometer (FWD) and the digital image processing technique [21]) should be employed together with, if necessary, laboratory analyses.

Among the most interesting techniques for removing previous defects, there are:

(a) the use of polyurethane resins to seal stones pavement joints in place of sand which on the one hand mutually joints adjacent stones, but on the other it can be permeable to water infiltration;

(b) the use of geotextiles to solve the problem with indepth material migrating upwards and drastically reduce the pumping effect;

(c) the track isolation from the adjacent pavement by means of proper material at high deformability and damping coefficient;

(d) the truck layers must be maintained with a constant thickness in order to minimise the risk of forming differential subsidence;

(e) the stone blocks must be laid so as to create longitudinal and transversal discontinuities, thus avoiding continuous joints; to this regard, interrupted joints, diagonal or fishbone layouts can be usefully employed.

\section{Conclusions}

The tramway transportation system in the urban context poses numerous problems, still unsolved to some extent, for the road safety and safeguard of "vulnerable users" (cyclists, pedestrians, disabled people), especially at road intersections which are intrinsically very critical areas both in terms of functionality and safety.

Accident risk data unequivocally indicate that the tramway transportation system as relatively safe (when compared to other modes of transport).

For example, in 2016 in Italy, there were in all 175,791 road accidents (with seriously injured casualties) but only 162 were accidents involving trams (46 one-vehicle crashes and 116 involving other vehicles).

Nevertheless, road safety aspects must not be underestimated. This is because in the next future a greater number of users are supposed to use the tramway transportation system and consequently tramlines will be significantly extended with further exposure to accident risks, especially in old town centres. In fact, the new ground-level power supply technologies and other types of catenary-free systems allow to build tramway lines, even in old town centres and pedestrian areas.

All that considered, the paper identifies the main accident risks for the different road users near tramways lines and the relative technical measures to be adopted on the basis of international experiences with the aim of eliminating or reducing the risks underlined above. The paper especially examines the accident cases involving trams and cars, pedestrians and cyclists/motorcyclists.

It has been found that the accidents at road intersections are correlated, among others, with the following aspects:

- road axles do not cross each other perpendicularly;

- users perform left-turn manoeuvre when the traffic light is red trying to anticipate the oncoming tram;

- users execute left-turn manoeuvre following a platoon of vehicles which have already performed the same manoeuvre, thus violating the tram right of way;

- users carry out left-turn manoeuvres immediately after the very end of the green light phase;

- users ignore the left/right-turn prohibition and intersect the tramway;

- users confuse tram and intersection sign systems;

- the intersection layout can determine errors in perception and/or behaviour;

- tramway truck defects.

The best techniques suitable to mitigate the risks and make roads with tramlines safer concern the following typical topics: road geometry, traffic regulations, traffic sign system, organisation of street furniture and tramway truck.

Generally, the main countermeasures to reduce accident risks are aimed at better warning road users (car drivers, pedestrians and cyclists) of specific risk conditions due to the tramway lines, above all near the road intersections. 
Other countermeasures are designed to install suitable facilities on road platforms for better informing users of tramway system, for limiting or temporarily prohibiting turning movements or manoeuvrings and for properly channelling pedestrian and vehicle flows with the purpose to avoid or reduce interference with trams.

Considering the high complexity level of the topic in question, it is advisable for the management bodies to perform specific safety analyses (like the "Road Safety Audit" and "Road Safety Review") in order to identify all the potential road safety problems for constructing new tramways, or upgrading those in operation, as well as all the technical countermeasures for their implementation.

Open Access This article is distributed under the terms of the Creative Commons Attribution 4.0 International License (http://crea tivecommons.org/licenses/by/4.0/), which permits unrestricted use, distribution, and reproduction in any medium, provided you give appropriate credit to the original author(s) and the source, provide a link to the Creative Commons license, and indicate if changes were made.

\section{References}

1. Vuchic VR (2007) Urban transit systems and technology. Wiley, Hoboken

2. Weinstein ND (1980) Unrealistic optimism about future life events. J Personal Soc Psychol 39:806-820

3. Castanier C, Paran F, Delhomme P (2012) Risk of crashing with a tram: perceptions of pedestrians, cyclists, and motorists. Transp Res Part F 15:387-394

4. Fontaine F, Novales M, Bertrand D, Teixeira M (2016) Safety and operation of tramways in interaction with public space. Transp Res Proc 14:1114-1123

5. Union Station (U.S.) (2013) Georgetown alternatives analysis propulsion study page. Final report. September 2013

6. Bieber C (1986) Les choix techniques pour les transports collectifs. Lecture notes. Ecole Nationale des Ponts et Chaussées, Paris

7. Pyrgidis C (2016) Railway transportation systems. CRC Press, Boca Raton

8. Swanson J, Smatlak J (2015) State-of-the-art in light rail alternative power supplies. Prepared for: APTA/TRB 2015 light rail conference
9. Guerrieri M, Ticali D (2012) Sustainable mobility in park areas: the potential offered by guided transport systems. ICSDC 2011: Integrating Sustainability Practices in the Construction Industry Proceedings of the International Conference on Sustainable Design and Construction 2011, Code 89278, pp 661-668. https:// doi.org/10.1061/41204(426)81

10. Guerrieri M, Ticali D (2012) Design standards for converting disused railway lines into greenways. ICSDC 2011: Integrating Sustainability Practices in the Construction Industry - Proceedings of the International Conference on Sustainable Design and Construction 2011, Code 89278, pp 654-660. https://doi.org/10. 1061/41204(426)80

11. Ministero delle Infrastrutture e dei Trasporti (2017) Conto Nazionale delle Infrastrutture e dei Trasporti Anni 2015-2016. Istituto Poligrafico e Zecca dello Stato S.p.A., Roma

12. Road accidents in Italy in 2017. ISTAT (2018) Istituto Nazionale di Statistica. https://www.istat.it/it/files/2018/07/Incidenti-stra dali_2017.pdf

13. Korve HW et al (1996) TCRP report 17: integration of light rail transit into city streets. Transportation Research Board, National Research Council, Washington, D.C.

14. Korve HW et al (2001) TCRP report 69: light rail service: pedestrian and vehicular safety. Transportation Research Board, National Research Council, Washington, D.C.

15. Pecheux KK et al (2009) TCRP synthesis 79: light rail vehicle collisions with vehicles at signalized intersections. A synthesis of transit practice. Transportation Research Board, Washington, D.C.

16. Naznin F, Currie G, Logan D (2018) Exploring road design factors influencing tram road safety-Melbourne tram driver focus groups. Accid Anal Prev 110:52-61

17. Mauro R, Cattani M, Guerrieri M (2015) Evaluation of the safety performance of turbo-roundabouts by means of a potential accident rate model. Baltic J Road Bridge Eng 10:28-38

18. Transportation Research Board (2000) Highway capacity manual-HCM 2000, special report n. Washington D.C.

19. Irwin D (2003) Safety criteria for light rail pedestrian crossings. In: 9th national light rail transit conference. Transportation Research Board, Washington, D.C.

20. Crispino $\mathrm{M}$ et al (2004) A new technique to increase the safety of stone pavements through controller evolution of unevenness. In: II International congress SIIV, Firenze-Italia

21. Guerrieri M, Parla G, Corriere F (2013) A new methodology to estimate deformations of longitudinal safety barrier. ARPN J Eng Appl Sci 8(9):763-769 